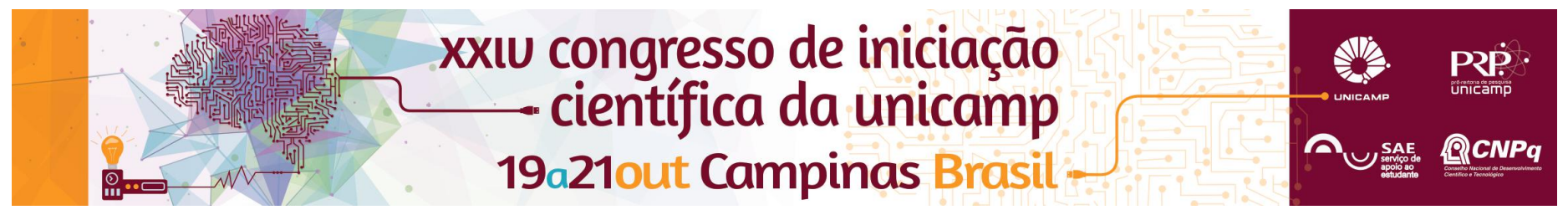

\title{
Equações de movimento de robô não holonômico com deslizamento
}

\author{
Thales G. Biancalana*, J. F. Camino
}

\section{Resumo}

Este projeto de iniciação científica teve por objetivo levantar o modelo dinâmico de um robô móvel não holonômico com deslizamento nas rodas. Para atingir esse objetivo, realizou-se primeiramente um estudo sobre cinemática de sistemas holonômicos e não holonômicos e suas restrições. Em seguida, foram estudadas as formulações de Newton, Lagrange, Maggi e Boltzmann-Hamel e suas aplicações na obtenção de modelos dinâmicos de sistemas holonômicos e não holonômicos. Esse estudo forneceu os conhecimentos técnicos necessários para a obtenção das equações diferenciais que representam a dinâmica do robô.

\section{Palavras-chave:}

Robôs móveis, sistemas não holonômicos, deslizamento.

\section{Introdução}

O movimento de um robô móvel pode ser representado de modo simplificado por modelos cinemáticos ou de forma mais completa por modelos dinâmicos. Em geral, modelos cinemáticos são obtidos a partir de equações de restrições que podem ser holonômicas, funções somente das coordenadas generalizadas, ou não holonômicas, funções das coordenadas e velocidades generalizadas ${ }^{1}$. As equações de movimento de um sistema dinâmico holonômico ou não holonômico podem ser obtidas através das formulações de Newton, Lagrange, Maggi e Boltzmann-Hamel ${ }^{2}$

No caso do sistema robótico estudado, que foi representado de modo simplificado por duas rodas paralelas ligadas por uma haste rígida, é interessante que as equações finais estejam em função das quasivelocidades, pois são úteis em aplicações de controle de sistemas robóticos em que geralmente se deseja controlar a velocidade das rodas do robô.

Um tempo significante da pesquisa foi dedicado ao estudo dessas formulações. Focou-se principalmente na análise das vantagens e desvantagens dessas técnicas, com relação à sua complexidade e a forma final das equações obtidas, que podem conter apenas as coordenadas generalizadas e suas derivadas em relação ao tempo ou podem também conter as quasivelocidades. Esse estudo foi importante pois possibilitou que as equações de movimento dos sistemas dinâmicos fossem derivadas usando-se formulações distintas, permitindo assim certificar se as equações diferenciais obtidas de fato estavam corretas.

\section{Resultados e Discussão}

Verificou-se que a formulação de Newton é a mais simples de ser aplicada, no entanto tem a desvantagem de requerer o conhecimento das resultantes agindo no sistema. Já a formulação de Lagrange, que é baseada em métodos de energia, é mais complexa, porém não é necessário determinar as reações internas do sistema. A formulação de Maggi, que também é baseada em métodos de energia, é mais complexa do que a de Lagrange, por incluir as quasi-velocidades, porém não é necessário determinar os multiplicadores de Lagrange e fornece exatamente as mesmas equações que os métodos de Newton e Lagrange. A formulação de Boltzmann-Hamel foi a formulação mais complexa estudada, mas é a única metodologia que fornece equações de movimento em função das quasivelocidades.

As equações de movimento do robô móvel, desconsiderando o deslizamento das rodas, foram obtidas através das formulações de Newton e Lagrange. Também foi determinada a equação de vínculo que representa o deslizamento do robô. Além disso, determinou-se na pesquisa que quando o fator de deslizamento das rodas do robô é conhecido tem-se uma equação de restrição e quando for desconhecido tem-se apenas um vínculo, que é uma relação entre coordenadas generalizadas, suas derivadas em relação ao tempo e variáveis desconhecidas.

Por fim, foram realizadas simulações numéricas das equações de movimento dos sistemas estudados utilizando o pacote ODE de integração de equações diferenciais ordinárias do software Matlab.

\section{Conclusões}

Foram estudadas as formulações de Newton, Lagrange, Maggi e Boltzmann-Hamel. Verificou-se que as formulações de Newton, Lagrange e Maggi fornecem equações de movimento idênticas, enquanto que a formulação de Boltzmann-Hamel fornece equações de movimento em função das quasi-velocidades. Portanto, este último método foi escolhido para ser utilizado na obtenção das equações de movimento do robô móvel.

\section{Agradecimentos}

Gostaria de agradecer aos meus pais por sempre me incentivarem a estudar e aprender, ao meu professor orientador por sempre me ajudar com as minhas dúvidas e sugerindo pontos de melhorias durante todo o ano de trabalho, e também ao CNPq pela bolsa concedida.

\footnotetext{
${ }^{1}$ Greenwood D. Classical dynamics. Englewood Cliffs, N.J.: Prentice-Hall; 1977.

${ }^{2}$ Greenwood D. Advanced dynamics. Cambridge, U.K.: Cambridge University Press; 2003
} 